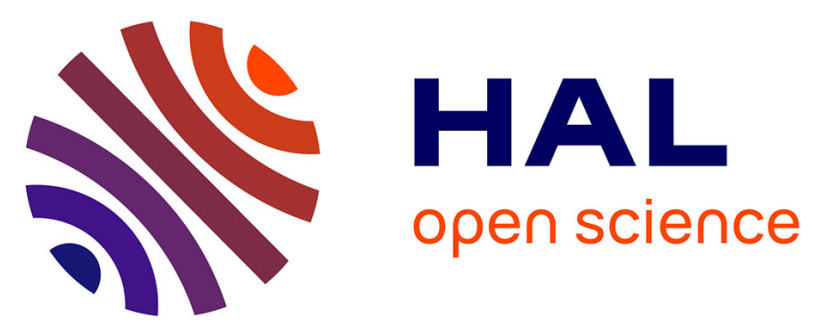

\title{
The State of Agile Software Development in the Czech Republic: Preliminary Findings Indicate the Dominance of "Abridged" Scrum
}

\author{
Michal Dolezel, Alena Buchalcevova, Michal Mencik
}

\section{- To cite this version:}

Michal Dolezel, Alena Buchalcevova, Michal Mencik. The State of Agile Software Development in the Czech Republic: Preliminary Findings Indicate the Dominance of "Abridged" Scrum. 13th International Conference on Research and Practical Issues of Enterprise Information Systems (CONFENIS), Dec 2019, Prague, Czech Republic. pp.43-54, 10.1007/978-3-030-37632-1_4 . hal-03408378

\section{HAL Id: hal-03408378 \\ https://hal.science/hal-03408378}

Submitted on 29 Oct 2021

HAL is a multi-disciplinary open access archive for the deposit and dissemination of scientific research documents, whether they are published or not. The documents may come from teaching and research institutions in France or abroad, or from public or private research centers.
L'archive ouverte pluridisciplinaire HAL, est destinée au dépôt et à la diffusion de documents scientifiques de niveau recherche, publiés ou non, émanant des établissements d'enseignement et de recherche français ou étrangers, des laboratoires publics ou privés.

\section{(c)(1)}

Distributed under a Creative Commons Attribution| 4.0 International License 


\title{
The State of Agile Software Development in the Czech Republic: Preliminary Findings Indicate the Dominance of "Abridged" Scrum
}

\author{
Michal Dolezel ${ }^{10000-0002-5963-5145]}$, Alena Buchalcevova1[0000-0002-8185-5208], Michal \\ Mencik $^{1}$ \\ Faculty of Informatics and Statistics, University of Economics, Prague, W. Churchill Sq. 4, \\ 13067 Prague, Czech Republic \\ \{michal.dolezel, alena.buchalcevova, menmo0\}@vse.cz
}

\begin{abstract}
This paper presents preliminary results from a survey focused on the state of agile method adoption in the Czech Republic. To this end, an initial survey sample $(\mathrm{N}=120)$ was analyzed. Scrum is the most frequently used agile software development method, reported by $46.7 \%$ of respondents as the agile method of choice. However, the results indicate that Scrum seems to be introduced through cherry-picking of those practices that are quite easy to implement. Specifically, the only widely-spread Scrum practice is the maintenance of Product backlog. To the contrary, the teams are rarely cross-functional and the Scrum master role frequently absents. This suggests that in many organizations, Scrum might be invoked due to being a valuable "brand name", rather than due to professionals' subscribing to core Scrum values and assumptions. Our results contribute to the body of empirical knowledge on the state of agile software development initiatives. Our findings confirm the theoretical proposition that in the real world, the implementation of software development methods is often patchy and rarely done "by the book".
\end{abstract}

Keywords: Software project management; Agile methods; Agile practices; Scrum practices; Scrum variations; Agile method tailoring; Hybrid methods.

\section{Introduction}

Software development and deployment activities are at the heart of many information systems initiatives. The academic disciplines in the field of computing have long been interested in the conceptual means that practitioners employ to manage those activities in everyday reality $[1,2]$. Of particular interest are presently agile software development methods (ASDMs), which are rapidly spreading across the world, irrespective of what the company's core business is [3]. Thanks to this advance, the interest in agile methods is growing also in a number of interrelated research areas, including Enterprise Resource Planning and business administration $[4,5]$. 
Striving to characterize the state of ASDM adoption, both scientists [3, 6-11] and practitioners [12] put effort into exploring the agile territories. However, only very limited data are available to speak about the up-to-date state of ASDM adoption in the Czech Republic. To close that gap, we designed and conducted a survey among Czech agile practitioners. On this basis, the present paper provides an overview of ASDMs used by them. To deliver preliminary findings, we analyze our initial survey sample $(\mathrm{N}=120)$ gathered over the period of 5 weeks. (At the time of writing, the survey was still on-going.)

At this stage of research, we have been particularly interested in the connection between ASDMs and software project management [13]. To this end, in this paper we present two categories of findings: (i) an overall summary of the coverage of different ASDMs in the Czech Republic; (ii) the data that characterize the local nature of Scrum, a generic software project management framework [14]. We then discuss the ways in which Scrum seems to be currently implemented in the surveyed population. As a matter of fact, we found a highly reductionist version of Scrum seeming to dominate in practice. We contribute to the body of knowledge by (i) describing the present state of ASDMs in the Czech Republic; (ii) a brief analysis of the Scrum adoption pattern observed. Our findings are useful for understanding the nature of differences between ideal ASDMs, viewed as generic templates, and the real instances of ASDMs as implemented by practitioners.

The paper is organized as follows. Following the Introduction, Section 2 reviews related work. Next, Section 3 describes our research approach. Section 4 then presents the survey results. Finally, Section 5 provides discussion and concluding remarks.

\section{Related Work}

To understand the current usage of ASDMs, a number of research strategies have been adopted. Typically, either qualitative $[15,16]$ or quantitative methods are employed. Less commonly, researchers also use action research frameworks [7]. To limit our focus only on the quantitative side, researchers make use of national-level surveys [11], global reach surveys [17] and surveys probing into a selected set of agile practices of certain kind [8]. A significant influence within the domain of industry practice is attributed to practice-based surveys which are administrated by large vendor and consulting companies [12]. Given the space constraints of this paper, we review below only the most relevant contributions from both categories, forming a conceptual basis for our research. We firstly take a look on relevant surveys from abroad (Section 2.1), followed by the surveys previously carried out in the Czech Republic (Section 2.2).

\subsection{State of ASDM Adoption Worldwide}

Generally speaking, a significant amount of survey results that describe the current state of ASDM adoption are available, but the coverage of various geographic territories highly differs. In 2012, among the first (see also [17]), Finish researchers conducted a large scale survey to portray the initial picture of ASDMs in an European context [11]. 
Similar surveys have been conducted also in entirely different geographical areas such as Brazil [18, 19]. In addition, researchers have tried to reach English-speaking populations across the globe by offering them survey instruments in English [10, 17]. Starting quite recently, valuable work has been carried out within the Hybrid dEveLopmENt Approaches (HELENA) research community. The goal of the initial phases of the initiative was to collect data on the nature of hybrid methods adoption, including both the sequential and agile ones. The survey was available in several languages and thus more accessible to non-English speaking practitioners [3]. Unfortunately, the survey did not attract attention of respondents from the Czech Republic.

In the world of business practice, the "State of Agile" survey with a global reach has been conducted by VersionOne (later CollabNet VersionOne) annually since 2006. Today, the survey is well-known to many agile practitioners. The recent $\left(13^{\text {th }}\right)$ edition [12] was carried out between August and December 2018. However, when considering the results reported by similar surveys, one should be cautious. In essence, many times those surveys may be designed in a way to support the core business of the vendor [11]. Also, the research method adopted may lack the necessary level of rigor.

\subsection{State of ASDM Adoption in the Czech Republic}

The results that would describe the state of ASDM adoption in the Czech Republic are quite rare. Yet, initial attempts to map the area were carried out in 2006 and 2009 [20, 21]. In 2013, two surveys were executed. The Czech company Etnetera replicated the VersioneOne survey in the Czech Republic [22]. Then, Tománek [23] collected data for his survey within a global logistics company. Although his findings have limited generalizability, he proposed that Czech practitioners seem to be among the laggards in ASDM adoption.

\section{Research Method}

In this section, we provide details on the construction and execution of our survey. In Section 3.1, we describe survey design. Then, in Section 3.2, we discuss the method of data collection.

\subsection{Survey Design}

The survey instrument contained 18 questions, including a large section devoted to concrete practices, and 4 optional (mostly free-text) answers. We divided the instrument into three logical parts:

- The first part consisted of (i) General demographic characteristics of respondents; (ii) Primary ASDM that the team uses; (iii) Estimated level of method tailoring; (vi) Perceived benefits of method use;

- The second part consisted of (i) Used agile practices (34 practices were offered - see below); (ii) Frequency of their usage within the team (a three-point Likert scale: 
"Used", "Used to a certain extent", "Not used", complemented by a "Don't know/Cannot be evaluated" option); (iii) Respondent's subjective scoring of the importance of the practices;

- Concluding demographics questions.

The analysis presented in this paper is centered around the list of 34 practices, derived by a synthes is of previous research $[3,19]$ and practitioner literature [12]. We put a particular attention to the practices introduced by the Scrum and XP originators [14, 24]. Giving some extra attention to DevOps, we added certain practices to the list. For example, we expected to capture significant differences in popularity among various "Continuous *" methods [25], and we therefore conceptually differed among them.

The survey form contained an instruction to relate the answers concerning the practices to a current or quite recent project (run either by their team, or a team that the respondents "work with"). Inversely, the respondents were asked to think about a potential importance of the practice from their personal perspective, i.e. irrespective of the fact whether the practice was currently used or not used by the team (this aspect is not analyzed here). The survey was available in the Czech language. However, for the sake of clarity and respondents' convenience, it contained also English equivalents of the names that commonly characterize the surveyed agile practices (e.g. "Tabule Kanban" was supplemented with "Kanban board" in smaller letters). The reason behind was that as part of their jargon, many Czech practitioners commonly use the original English terms instead of their formal Czech equivalents.

\subsection{Data Collection and Analysis}

Given certain pragmatic constraints (e.g. additional costs, current European privacy laws etc.), we opted for convenience sampling [26] in which social networks played a dominant role. While such a strategy suffers from clear drawbacks, it is relatively common in our domain of research.

In two waves, we shared the link to the survey in 17 professional and alumni LinkedIn and Facebook groups containing ca. 20,000 members (who were mostly Czechs or Slovaks) in total. This was followed by sharing the link with our industry contacts (ca. 50), either via LinkedIn messaging or by email. Here, we analyze the answers collected during the first 5 weeks (ending on 17 August 2019). We applied descriptive statistics.

\section{$4 \quad$ Results}

This section presents some initial results derived from the data sample described above. First, we give a summary of participant demographics (Section 4.1). In Section 4.2, we demonstrate what ASDMs are adopted, and to what extent. In Section 4.3, we take the dominant method (i.e. Scrum) and discuss the way in which the method seems to be implemented. 


\subsection{Participant Demographics}

Table 1 provides an overview of the survey respondents (only respondents who completed the survey, i.e. ans wered all mandatory questions, were included in our analys is). To give some additional details, our respondents were mostly from the domain of Information Technology/Software Development (40.0\%) and Finance (10.8\%). Other domains were less frequent ( $6 \%$ or less each).

Table 1. Respondents' job position and years of experience

\begin{tabular}{|c|c|c|c|c|c|c|}
\hline Job Position / Experience with ASDMs & $\begin{array}{l}\text { No hands-on ex- } \\
\text { perience }\end{array}$ & $<1 \mathrm{y}$ & 1 to $2 \mathrm{y}$. & 3 to $4 \mathrm{y}$. & $\begin{array}{l}5 \text { or } \\
\text { more y. }\end{array}$ & Total \\
\hline Product owner & & 1 & 6 & 5 & 6 & 18 \\
\hline Agile coach / Scrum master & & & 6 & 10 & 6 & 22 \\
\hline Member of the dev. team & 1 & 7 & 17 & 16 & 7 & 48 \\
\hline Other managerial IT role & & 3 & 3 & 4 & 8 & 18 \\
\hline Other managerial role & 1 & 1 & 1 & 3 & 1 & 7 \\
\hline Other business role & & & & 1 & 2 & 3 \\
\hline Other & & 2 & & & 2 & 4 \\
\hline
\end{tabular}

\subsection{Agile Methods Usage}

Figure 1 shows usage of various agile methods, as reported by our respondents. The most widely used agile method is Scrum, reported as the method of choice by $46.7 \%$. Scrum altogether with its agile extensions (i.e. Scrum/XP hybrid and Scrumban) counts for $65.0 \%$. Interestingly, the representation of Scrum combined with Waterfall (commonly called also Water-Scrum-Fall [27]) accounts only for $8.3 \%$. Large scale agile methods [7] were reported to be used by $16.7 \%$ of respondents.

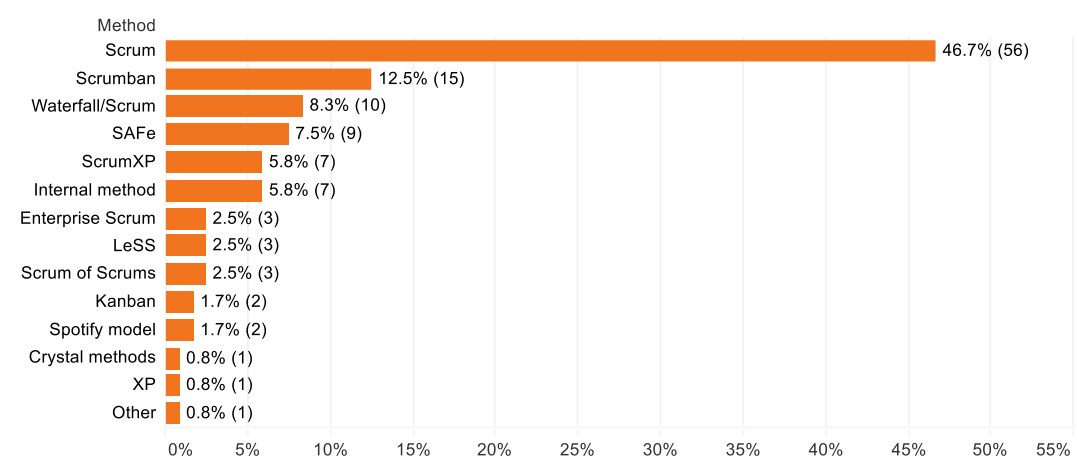

Fig. 1. Agile methods usage

The dominance of Scrum is in line with the CollabNet VersionOne survey [12], where Scrum (54\%) and agile Scrum hybrids (together with Scrum account for $72 \%$ ) 
were reported as the most widely-practiced agile method(s). The leading position of Scrum (87\%) was confirmed also by the Etnetera local survey [22] in 2013. Nevertheless, it is not possible to directly compare the relative representation of various agile methods with the latter survey. The reason is that Etnetera adopted a multi-choice questioning strategy regarding this aspect, while we opted for single-choice, being in-line with CollabNet VersionOne.

Figure 2 portrays what agile methods are used in companies of various sizes. At this point, we aggregated data for two common hybridized agile methods (i.e. Scrumban, ScrumXP), being represented by the Hybrid agile methods category. As obvious, Waterfall/Scrum forms a separate category. (We consider those implementations "not fully agile".) The category titled Large-scale agile includes Enterprise Scrum, LeSS, SAFe, Scrum of Scrums, and Spotify model.

The leading position of Scrum and its hybrids continues to be apparent across all company size segments. The relative popularity of the Watefall/Scrum hybrid slightly falls down with the growing company size. This trend seems to be due to an introduction of large scale agile methods, which are, not surprisingly, implemented especially in larger companies.

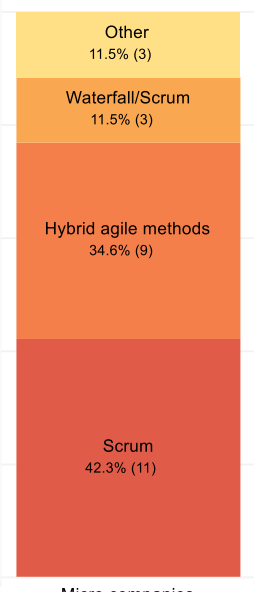

Micro companies

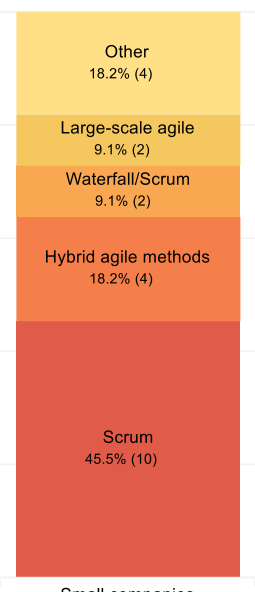

Small companies

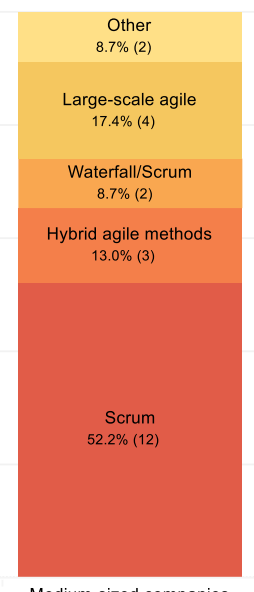

Medium-sized companies

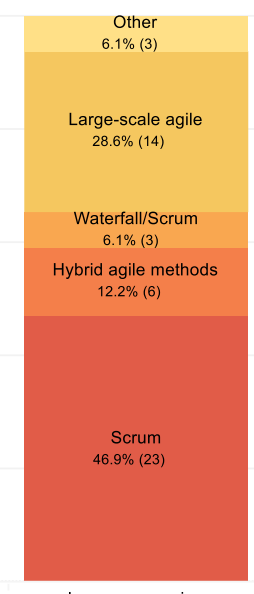

Large companies

Fig. 2. Agile methods usage per company size (Micro companies - less than 10 employees; Small companies - 10 to 49 employees; Medium-sized companies - 50 to 249 employ ees; Large enterprises -250 or more employees)

Figure 3 provides a look on the usage of 34 surveyed practices. As the term "practice" is used in a broad sense, these were specifically either engineering practices (e.g. Pair programming), organizational practices (e.g. Iteration planning) and organizational patterns (e.g. Open office), or team-work tools (e.g. Kanban board). Product backlog is by far the most used agile practice utilized by almost all teams (98.3\% use it fully or partially). By contrast, Behavior Driven Development (BDD) and Test-Driven Development (TDD) are the least used agile practices (only $22.5 \%$ use fully or partially BDD, and 28.3\% TDD). 


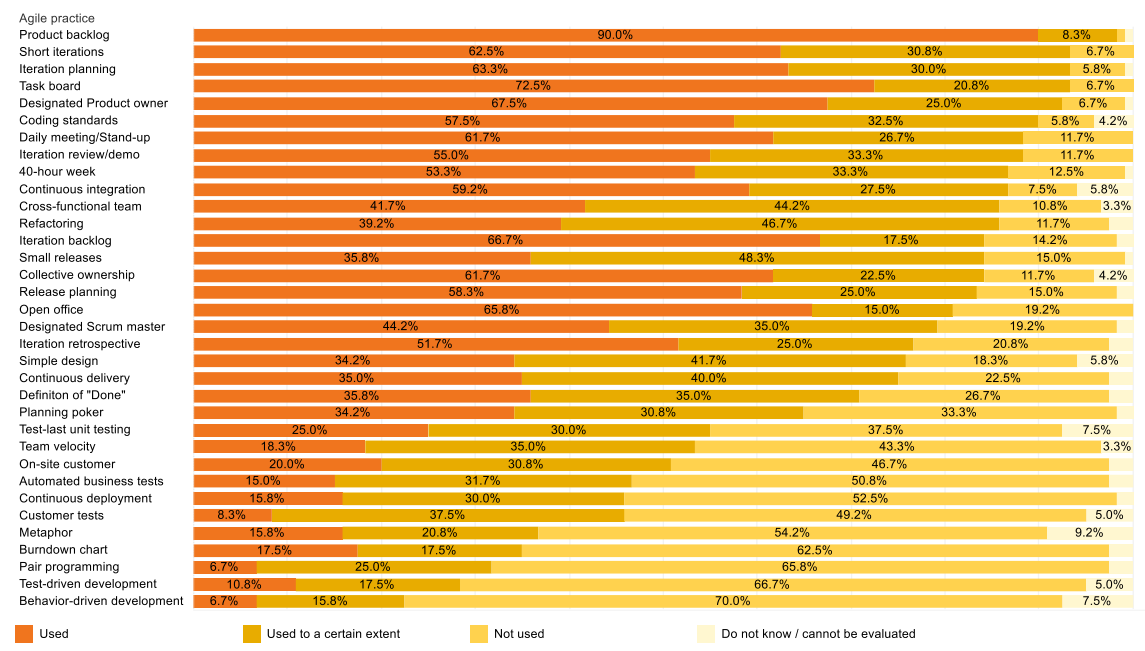

Fig. 3. Agile practices usage

Next, we analysed the practices reported by CollabNet VersionOne [12] as the most widely used within two specific categories. First category covers three organizational practices (termed by their survey as "agile techniques") and second category contains three engineering practices. In Table 2, we compare those data with the relevant data from the former Czech industry survey conducted by Etnetera [22], the HELENA study [6], and our survey. Except for the comparison with HELENA (see below), there are no striking differences in the category of organizational practices among the surveys. An interesting finding is that in the Czech Republic the usage of the three top agile techniques slightly increased between 2013 and 2019 (as reported by Etnetera and our survey respectively). This may speak for agile implementations becoming more mature.

Table 2. Usage of top-3 organizational and engineering practices (a comparison with VersionOne as a baseline)

\begin{tabular}{lcccc}
\hline & $\begin{array}{c}\text { VersionOne } \\
\text { (World) }\end{array}$ & $\begin{array}{c}\text { Etnetera } \\
(\mathrm{CZ})\end{array}$ & $\begin{array}{c}\text { HELENA } \\
\text { (World) }\end{array}$ & $\begin{array}{c}\text { Our study } \\
\text { (CZ) }\end{array}$ \\
\hline Organizational practices & & & & \\
$\quad$ Daily standup & $86 \%$ & $79 \%$ & $79.7 \%$ & $\mathbf{8 8 . 4 \%}$ \\
$\quad$ Sprint/iteration planning & $80 \%$ & $86 \%$ & $82.4 \%$ & $\mathbf{9 3 . 3 \%}$ \\
$\quad$ Retrospectives & $80 \%$ & $69 \%$ & $77.9 \%$ & $\mathbf{7 6 . 7 \%}$ \\
Engineering practices & & & & \\
$\quad$ Unit testing & $69 \%$ & $67 \%$ & $86.7 \%$ & $\mathbf{5 5 . 0 \%}$ \\
$\quad$ Coding standards & $58 \%$ & $41 \%$ & $93.4 \%$ & $\mathbf{9 0 . 0 \%}$ \\
$\quad$ Continuous integration & $53 \%$ & $55 \%$ & $84.5 \%$ & $\mathbf{8 6 . 7 \%}$ \\
\hline
\end{tabular}

As of the usage of engineering practices, the differences among the surveys are significant. Notably, the differences between the Etnetera survey and our survey are of 
interest. First and foremost, it is surprising to see the low adoption rate of unit testing, as reported by our respondents. Given that unit testing has long been considered a vital practice in software development, one may certainly wonder why so many surveyed teams (37.5\%) do not employ such practice at all (Fig. 3).

Next, we focus on the remaining engineering practices (i.e. Continuous integration and Coding standards) and possible explanations for the differences in the results between 2013 and 2019. First, we speculate that there might be a causal relationship between the high use of Continuous Integration and Coding standards. This could be an effect of the following pattern: Checking compliance to coding standards automatically (i.e. through the means of the continuous integration process - during every code commit) is nowadays considered, in general, a good practice [28]. Hence, regarding those two engineering practices, we broadly as sume that the increased proportion of their use may go hand-in-hand with the growing popularity of continuous software engineering in the recent years [25].

Looking from a different perspective, we propose that the differences between the research methods adopted in our survey and the Etnetera survey might account for an alternative explanation. In ourcase, the respondents were provided with the Likert scale described in Section 3.1. By contrast, Etnetera seems to had queried their respondents using a simple yes/no logic. This methodological variance could have caused that a number of undecided respondents in our study were inclined to answer "Used to a certain extent" instead of "No". In our understanding, such respondents or their teams might be currently just experimenting with the practices.

The reason for employing the 3-point scale was to give respondents a possibility to indicate that the practice was not (yet) fully instituted. A similar approach was chosen in the HELENA study, in which even a more complex scale ("rarely used", "sometimes used", "often/always used") was implemented [6]. In essence, we wanted to understand whether there is a possibility to discriminate between "easy" and "complicated" practices. In that regard, we want to briefly highlight the following fact. The practices with the lowest "Used to a certain extent"/"Used" ratio (exact calculations are not included here) are Product backlog and Open office. These appear to be easily implementable practices. The practices scoring with high ratios (e.g. Small releases or Refactoring) are arguably technically demanding and teams might struggle with their implementation.

Regarding an additional comparis on with HELENA, it is important to highlight that the interest of the HELENA study has not been limited to agile projects. That means, the HELENA data contain also such responses collected concerning hybrid projects (i.e. projects with a presumable planning-oriented component). Interestingly, except for unit testing, the differences between the presented HELENA results and our results are not very significant. This finding, however, applies only to six practices from the presented baseline. Looking beyond that would allow for rendering additional significant differences (e.g. regarding the usage of Burndown chart).

\subsection{Nature of Scrum}

Table 3 allows for deriving certain conclusions about the form of Scrum the teams use in practice. 
Table 3. Usage of agile practices in teams with "pure" Scrum ( $\mathrm{N}=56)$. Q1: Dominant practices (used by 75-100\%); Q2: Mainstream practices (used by 50-75\%); Q3: Marginalized practices (used by 25-50\%); Q4: Absenting practices (used by 0-25\%).

\begin{tabular}{lllll}
\hline \multicolumn{2}{l}{ Scrum practice } & Used & \multicolumn{2}{l}{ Used to a certain ex- } \\
& & tent & Total \\
\hline Q1 & Product backlog & $85.7 \%(48)$ & $10.7 \%(6)$ & $96.4 \%(54)$ \\
& Iteration planning & $67.9 \%(38)$ & $28.6 \%(16)$ & $96.4 \%(54)$ \\
& Iteration backlog & $67.9 \%(38)$ & $16.1 \%(9)$ & $83.9 \%(47)$ \\
& Daily meeting/Stand-up & $67.9 \%(38)$ & $17.9 \%(10)$ & $85.7 \%(48)$ \\
Q2 & Short iterations & $64.3 \%(36)$ & $32.1 \%(18)$ & $96.4 \%(54)$ \\
& Designated Product owner & $62.5 \%(35)$ & $26.8 \%(15)$ & $89.3 \%(50)$ \\
& Iteration retrospective & $57.1 \%(32)$ & $23.2 \%(13)$ & $80.4 \%(45)$ \\
& Iteration review/demo & $51.8 \%(29)$ & $32.1 \%(18)$ & $83.9 \%(47)$ \\
& Definition of "Done" & $44.6 \%(25)$ & $35.7 \%(20)$ & $80.4 \%(45)$ \\
Q3 & Designated Scrum master & $37.5 \%(21)$ & $42.9 \%(24)$ & $80.4 \%(45)$ \\
& Cross-functional team & $33.9 \%(19)$ & $50.0 \%(28)$ & $83.9 \%(47)$ \\
Q4 & Burndown chart & $16.1 \%(9)$ & $21.4 \%(12)$ & $37.5 \%(21)$ \\
\hline
\end{tabular}

To derive stronger conclusions, we wanted to differ deep-rooted practices from those used by the teams only rarely or those which might be considered as dysfunctional. Hence, differently from the above analysis of agile practices, at this point we focus on the answers that indicate confidence in the usage of a practice (i.e. when the practice was reported as "Used"). We took all common Scrum practices [14, 29] from our list of 34 practices and grouped them into four quartiles, according to their representation (see the table caption for details).

Based on this framing, the only practice considered as dominant is keeping of Product backlog. By contrast, the practice which absents from use is Burndown chart, i.e. the visual tracking of remaining development work. For many, this finding may be surprising. Given that the Scrum originators argue that projective practices "have proven useful" [29], we consider the latter practice an important part of Scrum.

As marginalized we label the practices as follows: Cross-functional team, Scrum master, Definition of "Done". The low usage of the former practices is particularly interesting, because it indicates the way in which Scrum is implemented from an organizational standpoint. The originators of Scrum claim [29]: "Scrum Teams are selforganizing and cross-functional"; "The Scrum Master is responsible for promoting and supporting Scrum as defined in the Scrum Guide". In our survey, we did not explicitly ask for a pattern of self-organization. However, we did guide respondents in terms of stating that cross-functional teams are "usually self-organized". Indeed, the above data seem to portray a picture of ritual-centred implementations of Scrum [30], cherry-picking only those practices that are easy to implement. The truth is that a shift from directive management styles to self-organization have proven difficult for some enterprises [15]. Moreover, the frequent absence of Scrum master-a servant, non-directive leadership role-reported by our research seems to confirm the proposition. In that regard, an interesting question to ask is: Who is the keeper of the agile spirit in such 
teams? If this is the project manager, the question is whether we can still talk about Scrum in the sense of what Scrum originators have been using the term for [29]. In general, previous research shows that core responsibilities and the form of authority of the Scrum master role highly vary across different companies [16].

Surprisingly, the present study reports that combinations of Scrum and Waterfall (i.e. less-purist versions of Scrum) are employed infrequently. Together, this seems to show that many practitioners might be entirely unknowledgeable about the original intentions of Scrum originators, and the underlying values and assumptions they have promoted. In that sense, instead of "being agile", the practitioners might be just "doing agile" [31].

\section{Discussion and Conclusion}

Today, research into software development and project management methods represents an important theme in a number of academic disciplines. This paper presents preliminary results that characterize the current state of ASDM adoption in the Czech Republic. In this stage, our aim has was share certain initial observations with researchers and practitioners, not to provide an all-encompassing analysis. We summarize the key finding as follows: Scrum clearly dominates among the ASDMs implemented in the Czech Republic, but perhaps it is a different form of Scrum than its originators have had in mind [29, 31].

We offer a possible explanation. As Scrum is rapidly gaining ground in the world of project management, it is increasingly being added to the repertoire of "traditional" project managers. Previously, these profes sionals might have used heavy-weight methods such as PMBOK or PRINCE2, possibly together with a "command \& control" mentality [15]. The ever-growing popularity of Scrum might have caused that differently from the intentions of its originators, the project managers have tended to implement Scrum in a utilitarian sense - as a "great tool" that appears to be simple and easy (in fact, it appears to be significantly easier than the above methods). However, Scrum is "Simple to understand", but "Difficult to master" [29]. This is to underscore the importance of the "soft" element in Scrum, i.e. psychology of the development team. In that sense, Scrum's simplicity may be merely an illusion.

Regarding the relationship between ASDMs seen as generic "brand labels" and concrete agile practices that are used in reality, the situation is complex. Previous research argues that in the real world practices are frequently used in quite creative ways and hardly ever "by the book" [6]. However, a too-relaxed form of ASDM implementation may easily result in disconnecting the practices from the "parental" ASDM, which they were conceptually bound with. In fact, such a pattern seems to presently be a general trend in software development - some authors even convincingly argue that practices should be officially "liberated [i.e. disconnected] from the methods that use themtheir method prisons" [32]. If we are to accept this argument, we will not be surprised by the level of creativity practitioners exhibit when adopting ASDMs for their unique 
contexts. Nevertheless, a contrarian argument may be as follows. Decoupling the practices from the core values and assumptions embodied by the ASDMs could lead to "ritualistic imitation of certain behavior" [30], entirely missing the ASDM essence [31].

Prior concluding, we admit that this paper suffers from several limitations. First, the analytical apparatus employed here is quite simple. Despite this fact, we believe that sharing the results with the community in a timely manner is important, because the results shed some light upon the somewhat controversial state of ASDM adoption in the Czech Republic. Second, in our survey we employed convenience sampling. While this approach is common in the domain of ASDM surveys $[3,6,11]$, the sample size is the main limiting factor also in our case [26]. Connected with this, we made use of social networks for the purpose of survey distribution. This certainly introduced a form of bias, limiting the possibility of participation to those who use that media. Third, from the quantitative data, it is hard to understand the exact reasons behind the "Used to a certain extent" answers. In our subsequent research, we therefore want to focus on the analysis of respondents' perceptions by employing a qualitative lens.

Acknowledgement. This work has been supported by an internal grant funding scheme (F4/23/2019) administered by the University of Economics, Prague.

\section{References}

1. Cusumano, M., Maccormack, A., Kemerer, C.F., Crandall, B.: Software Development Worldwide: The State of the Practice. IEEE Softw. 20, 28-34 (2003).

2. Fitzgerald, B.: An empirical investigation into the adoption of systems development methodologies. Inf. Manag. 34, 317-328 (1998).

3. Kuhrmann, M., Diebold, P., Munch, J., Tell, P., Trektere, K., Mc Caffery, F., Vahid, G., Felderer, M., Linssen, O., Hanser, E., Prause, C.: Hybrid Software Development Approaches in Practice: A European Perspective. IEEE Softw. 36, 20-31 (2019).

4. Kraljić, A., Kraljić, T.: Agile software engineering practices and ERP implementation with focus on SAP activate methodology. In: BIR. pp. 190-201 (2018).

5. Birkinshaw, J.: What to Expect From Agile. MIT Sloan Manag. Rev. 59, 39-42 (2018).

6. Klünder, J., Hebig, R., Tell, P., Kuhrmann, M., Nakatumba-Nabende, J., Heldal, R., Krusche, S., Masud, F.-B., Felderer, M.: Catching up with Method and Process Practice: An Industry-Informed Baseline for Researchers. In: 41st International Conference on Software Engineering: Software Engineering in Practice. pp. 255-264 (2019).

7. Kalenda, M., Hyna, P., Rossi, B.: Scaling agile in large organizations: Practices, challenges, and success factors. J. Softw. Evol. Process. 30, e1954 (2018).

8. Ochodek, M., Kopczyńska, S.: Perceived importance of agile requirements engineering practices - A survey. J. Syst. Softw. 143, 29-43 (2018).

9. Williams, L.: What agile teams think of agile principles. Commun. ACM. 55, 71 (2012).

10. Vijayasarathy, L.R., Dan Turk, C.: Agile software development: A survey of early adopters. J. Inf. Technol. Manag. XIX, 1-8 (2008).

11. Rodríguez, P., Markkula, J., Oivo, M., Turula, K.: Survey on agile and lean usage in Finnish software industry. In: ESEM. pp. 139-148 (2012). 
12. VersionOne, C.: 13th annual State of Agile report, https://www.stateofagile.com/\#ufhi-521251909-13th-annual-state-of-agile-report/473508, (2018).

13. Stellman, A., Greene, J.: Applied Software Project Management. O'Reilly Media, Beijing (2005).

14. Schwaber, K.: Agile Project Management with Scrum. Microsoft Press (2004).

15. Taylor, K.J.: Adopting Agile software development: the project manager experience. Inf. Technol. People. 29, 670-687 (2016).

16. Diebold, P., Ostberg, J.-P., Wagner, S., Zendler, U.: What Do Practitioners Vary in Using Scrum? In: XP. pp. 40-51 (2015).

17. Kurapati, N., Sarath, V., Manyam, C., Petersen, K.: Agile Software Development Practice Adoption Survey. In: XP. pp. 16-30 (2012).

18. Cesa, L.O.A., Mantovani Fontana, R., Reinehr, S., Malucelli, A.: Are We Agile or Not? A Survey on Brazilian Software Processes. In: WBMA.pp. 19-33 (2018).

19. Campanelli, A.S., Camilo, R.D., Parreiras, F.S.: The impact of tailoring criteria on agile practices adoption: A survey with novice agile practitioners in Brazil. J. Syst. Softw. 137, 366-379 (2018).

20. Buchalcevova, A.: Research of the Use of Agile Methodologies in the Czech Republic. In: Information Systems Development.pp. 51-64 (2009).

21. Šchová, Z.: Agile Adoption Survey 2009, http://soch.cz/AgileSurvey.pdf, (2009).

22. Průzkum agilního ř́zení v ČR, https://archiv.etnetera.cz/52591stahnout_agilni_report_2013/, (2013).

23. Tománek, M.: Současný stav používání agilních metodik ve světě a v ČR. Acta Inform. Pragensia. 4, 4-17 (2015).

24. Beck, K., Andres, C.: Extreme Programming Explained: Embrace Change. Addison Wesley, Boston, MA (2005).

25. Fitzgerald, B., Stol, K.-J.: Continuous software engineering: A roadmap and agenda. J. Syst. Softw. 123, 176-189 (2017).

26. Etikan, I., Abubakar Musa, S., Sunusi Alkassim, R.: Comparison of Convenience Sampling and Purposive Sampling. Am. J. Theor. Appl. Stat. 5, 1-4 (2016).

27. Schlauderer, S., Overhage, S., Fehrenbach, B.: Widely Used but also Highly Valued? Acceptance Factors and Their Perceptions in Water-Scrum-Fall Projects. In: Thirty Sixth International Conference on Information Systems. pp. 1-19 (2015).

28. Gmeiner, J., Ramler, R., Haslinger, J.: Automated Testing in the Continuous Delivery Pipeline: A Case Study of an Online Company. In: Eighth International Conference on Software Testing, Verification and Validation Workshops (2015).

29. Schwaber, K., Sutherland, J.: Scrum Guide, https://scrumguides.org/, (2017).

30. Mäki-Runsas, T.E., Wistrand, K., Karlsson, F.: Cargo Cults in Information Systems Development: A Definition and an Analytical Framework. In: Andersson, B. (ed.) Advances in Information Systems Development. pp. 35-53 (2019).

31. Hohl, P., Klünder, J., van Bennekum, A., Lockard, R., Gifford, J., Münch, J., Stupperich, M., Schneider, K.: Back to the future: origins and directions of the "Agile Manifesto"views of the originators. J. Softw. Eng. Res. Dev. 6, 1-27 (2018).

32. Jacobson, I., Lawson, H., Ng, P.-W., McMahon, P.E., Goedicke, M.: The Essentials of Modern Software Engineering. ACM (2019). 